\title{
Review for Uma escola atraente é um convite para estudar: Erasmo Pilotto e a educação paranaense na década de 1950.
}

\author{
Desiré Luciane Dominschek ${ }^{1}$ \\ ${ }^{1}$ Ensino \& Pesquisa
}

July 8, 2020

Resumo: Este é um Grupo de Revisores de pré-impressão da Revista Ensino \& Pesquisa. O texto avaliado foi Uma escola atraente é um convite para estudar: Erasmo Pilotto e a educação paranaense na década de 1950, de Márcia Marlene Stentzler e Cláudia Sena Lioti.

O artigo das autoras Marcia Stentzler e Claudia Sena Lioti aborda aspectos da história da Educação do Paraná, configurando a história a partir de Erasmo Pilotto intelectual da educação com expressão no Paraná no início do século XX. O artigo bem estruturado tem excelentes referencias que são base na área de história da educação , como Bourdieu (1998, 2007); Le Goff (2003); Miceli (2007).A pesquisa trabalha com as categorias de analise sobre o intelectual, considerando o capital sociocultural, para destacar a influência da escola nova. O trabalho, resgata a trajetória de Erasmo Pilotto, colocando em foco sua experiência de vida e formação acadêmica em prol da educação no Paraná. A pesquisa destaca a importância da área de história da educação no Brasil e no Paraná, evidencia o quanto é necessário os percursos históricos e biográficos dos intelectuais que estiveram a frente de processos educativos escolarizados, para análise critica sobre a constituição do processo de escolarização no Brasil, e em específico no Paraná! Conforme indicam as autoras em sua pesquisa Erasmo Pilotto fez parte do grupo de intelectuais que trabalhou em prol de uma escola pública unificada, laica e ativa no Estado do Paraná. À luz dos princípios da Escola Nova e experiências exitosas em outros Estados, como por exemplo Rio de Janeiro, São Paulo e Bahia, num momento histórico em que o discurso governamental era pela modernização e democratização, a educação era a ponte para alcançar esses resultados, conforme demonstram pesquisas de Miguel (1994), Vieira e Marach (2007), Silva (2009, 2014) e Monteiro (2015), entre outras.

O artigo tem o objetivo de compreender aspectos do pensamento de Pilotto e sua ação pedagógica a partir do capital sociocultural acumulado. Ainda as autoras investigam as origens e vivências que perpassaram a prática do educador, cujo trabalho se entretece ao percurso histórico e educacional do Estado, até meados do século XX. O artigo tem três tópicos, o primeiro discute a conjuntura paranaense da época: As primeiras décadas do Século XX no Paraná e a influência do intelectual, Conforme indica Stentzler (2015) o final da primeira década do século XX marcou o sul do Paraná e norte de Santa Catarina pela conclusão da ferrovia que ligava São Paulo ao Rio Grande do Sul. Os estados do Paraná e Santa Catarina viviam um clima conflituoso, de disputa territorial e, no ano de 1910, o Estado do Paraná perdia, novamente, recurso e embargo judicial para Santa Catarina quanto a posse do território do Contestado. O clima de conflito se acirrava, culminando na Guerra do Contestado, entre 1912 e pelo menos 1916, envolvendo sertanejos, forças governamentais e milicianos, entre outros.

Na região sul do Paraná, numa localidade hoje pertencente ao município de Rebouças, nascia Erasmo Pilotto, no ano 1910, (SILVA, 2009). Naquela região, o trem já trafegava há pelo menos 5 anos. A ferrovia simbolizava o progresso e a modernização para as cidades e populações do interior do Estado do Paraná. O segundo tópico elabora a a figura de Pilotto: Erasmo Pilotto: uma trajetória pela educação, Erasmo: um educador de alma 
romântica, obra escrita por Anita Camargo Pilotto (1987), a autora descreve suas atitudes profissionais por meio de anotações extraídas de seu diário. No entendimento da autora, Erasmo era possuidor de uma alma romântica. (PILOTTO, 1987). A amorosidade de sua esposa também revelava seu capital sociocultural e os seus bens simbólicos, nesta perspectiva, atribuímos à Erasmo Pilotto preocupação com uma verdadeira transformação social por meio da educação. O terceiro tópico apresenta o movimento escola nova na vida e obra desse intelectual.

Erasmo Pilotto lutou pela inserção das ideias da Escola Nova no Paraná, assim como em outros estados e em âmbito nacional, Fernando Azevedo (1894-1974), Lourenço Filho (1897-1970), Anísio Teixeira (19001971) e outros representam a busca por transformações curriculares na educação, tendo por base os ideais do escolanovismo. Segundo Vieira e Marach (2007, p. 270), estes educadores são "um exemplo sem precedentes na história brasileira do poder de mobilização da causa educacional na formação de um grupo de intelectuais sofisticados e, sobretudo, influentes na sociedade brasileira". Consideradas as especificidades da pesquisa, as representações acerca da educação e concepções teóricas podem ser compreendidas a partir de condições sociais favoráveis "à separação e divisão do trabalho simbólico", uma vez que a "atividade teórica, repousa, portanto, no privilégio" de ser lugar para compreender determinações, fatos simbólicos que correspondam à realidade, (MICELI, 2007, p. XXXVII). O trabalho é significativo para a área de história da Educação e conforme considerações finais da autora a perspectiva bourdieusiana, Erasmo Pilotto superou a expectativa do seu grupo social e alcançou a fração intelectualizada da elite paranaense. Ele foi um agente intelectual e político que, com sensibilidade e espírito científico, logrou importantes renovações e fez parte de uma profunda mudança nos paradigmas da educação do nosso Estado.

\section{References}

BLOCH, Marc. Apologia da História ou o ofício do historiador. Rio de Janeiro: Jorge Zahar Editora, 2001.

BOURDIEU, Pierre. Escritos de Educação. Petrópolis: Vozes, 1998.

BOURDIEU, Pierre. A economia das trocas simbólicas. Introdução, organização e seleção Sergio Miceli. São Paulo: Perspectiva, 2007. (Coleção estudos).

DEWEY, John. Experiência e educação. 3.ed. São Paulo: Ed. Nacional, 1979. GADOTTI, Moacir. História das Ideias Pedagógicas. São Paulo: Ática, 1996.

HUSS, Silvana Rodrigues Malheiro. O processo de escolarização no município de Mandaguari-Pr (1949-1988). Dissertação (Mestrado em Educação). Programa de Pós-graduação em Educação da Universidade Estadual de Maringá. 2012.

LAZIER, Hermógenes. Paraná: Terra de todas as gentes e de muita história. Francisco Beltrão: Grafit-gráfica e Editora Ltda, 2003.

LE GOFF, Jacques. História e Memória. 5. ed. Campinas, SP: UNICAMP, 2003.

MEC. INEP. CILEME. A educação do Paraná: síntese sobre o ensino público elementar e médio. No.3. Rio de Janeiro, 1954. (Série de monografias sobre os sistemas estaduais de educação).

MICELI, Sergio. Introdução. In: BOURDIEU, Pierre. A economia das trocas simbólicas. Introdução, organização e seleção Sergio Miceli. São Paulo: Perspectiva, 2007. (Coleção estudos).

MIGUEL, Maria Elisabeth, Blanco. A formação do professor e a organização social do trabalho. Curitiba: UFPR, 1997.

MIGUEL, Maria Elisabeth, Blanco. O significado do trabalho de Erasmo Pilotto no cenário educacional paranaense. In: Educar em Revista. n.10. Curitiba: UFPR, 1994.

MONTEIRO, Cicília Rodrigues. Contribuições de Erasmo Pilotto para expansão do ensino primário no Paraná: ensino rural, alfabetização e formação de professores (1940-1970). 91 f. Dissertação (Mestrado em Educação). Programa de Pós-graduação em Educação da Universidade Estadual de Maringá. 2015. 
MONTEIRO, Cicília Rodrigues; SCHELBAUER, Analete Regina. Erasmo Pilotto a idealização da escola perfeita: a criação do Instituto Pestalozzi. In: Seminário do PPE. Universidade Estadual de Maringá. Maringá: UEM, 2015.

OLIVEIRA, Maria Cecília Marins. Organização Escolar no início do século XX: o caso do Paraná. In: Educar em Revista. No. I 8. Curitiba: UFPR, 2001. pp. 143-155.

PILOTTO, Anita. Erasmo: um educador de alma romântica. Curitiba: Editora Rocha, 1987.

PILOTTO, Erasmo. Prática de Escola Serena. Curitiba: [s.l.],1946. PILOTTO, Erasmo. A educação é direito de todos. Curitiba: [s.l.], 195

PROSSER, Elizabeth Seraphim. Cem anos de sociedade, arte e educação em Curitiba (1853-1953): da Escola de Belas Artes e Indústrias, de Mariano de Lima, à Universidade do Paraná e à Escola de Música e Belas Artes do Paraná. Curitiba: Ed. Assembleia Legislativa do Paraná, 2004.

PUGLIELLI, Helio de Freitas. Erasmo Pilotto. Curitiba: Editora da UFPR, 1996. (Série Paranaenses, n. 7).

RELATÓRIO da Instrução Pública do Paraná, 1928. Disponível em https : //www . arquivopublico . pr . gov . br/arquivos/File/RelatoriosSecretarios/Ano_1928_MFN_1038.pdf . Acesso em: 21 de maio de 2020.

ROMANOVSKI, Natália. Os moços da província: a Revista Joaquim e o campo literário no Paraná. Monografia. Curso de Ciências Sociais, Setor de Filosofia, Ciências Humanas e Letras, Universidade Federal do Paraná. Curitiba, 2008.

SANTOS, Denise Grein (org). Autobiografia: Erasmo Pilotto. Curitiba, PR: UFPR, 2004. SILVA, Rossano. A arte como princípio educativo: um estudo sobre o pensamento educacional de Erasmo Pilotto. Dissertação (Mestrado em Educação) - Universidade Federal do Paraná, Curitiba, 2009.

SILVA, Rossano. Educação, Arte e Política: a trajetória intelectual de Erasmo Pilotto. 2014. Tese (Doutorado em Educação) - Universidade Federal do Paraná, Curitiba, 2014.

STENTZLER, Márcia Marlene. Entre questões lindeiras e a superação de fronteiras: a escola complementar em Porto União (SC) e União da Vitória (PR)1928-1928. 2015. Tese (Doutorado em Educação). Programa de Pós-Graduação em Educação da Universidade Federal do Paraná, Curitiba, 2015.

VIEIRA, Carlos Eduardo; MARACH, Caroline Baron. Escola de Mestre único e a escola serena: realidade e idealidade no pensamento de Erasmo Pilotto. In: VIEIRA, Carlos Eduardo (org.). Intelectuais, educação e modernidade no Paraná. Curitiba: UFPR, 2007.

XAVIER, Luiz Antonio. Relatório Apresentado a Exmo. Sr. Francisco Xavier da Silva, Presidente do Estado do Paraná. Curityba: Typ. Da República, 1910. Disponível em: http://www.arquivopublico.pr.gov.br/ arquivos/File/RelatoriosSecretarios/Ano_1910_MFN_743.pdf Acesso em: 17de maio de 2020.

XAVIER, Luiz Antonio. Relatório Apresentado a Exmo. Sr. Francisco Xavier da Silva, Presidente do Estado do Paraná. Curityba: Typ. Da República, 1911. Disponível em: https://www.scielo.br/scielo.php? script=sci_nlinks\&ref=000111\&pid=S0104-4060200100020000800045\&lng=en Acesso em: 24 de maio de 2020 . 